\title{
Marital Matching Among Immigrants: A Multidimensional Approach
}

Claudia Smith Kelly, Grand Valley State University, USA Sonia Dalmia, Grand Valley State University, USA

\begin{abstract}
This paper utilizes Becker's theory of efficient marriage markets to investigate the patterns of marital matching in marriages between two immigrants and between an immigrant and a U.S. native-born. It employs the Integrated Public Use Microdata Series of the 2000 Census and finds support for positive assortative mating on age and education and negative assortment along income and/or hours worked. The results from estimated match matrices employing multiple individual traits reveal that while native-born men are more likely to marry immigrant women with similar traits, native-born women are least likely to marry immigrant men with similar traits when compared to the immigrant-immigrant matches.
\end{abstract}

Keywords: Marital assignments, immigrants, market efficiency

\section{INTRODUCTION}

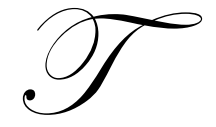

his paper examines marital matching patterns amongst immigrants residing in the United States using data from the Integrated Public Use Microdata Series of the 2000 U.S. Census. The empirical approach relies on Becker's theory of efficient marriage markets in which marital matching is based on household production (Becker, 1973, 1974). Efficient marriage markets maximize total marital output. To maximize marital output, multiple inputs, such as individual traits, are used in the household production function. The efficient marriage market model predicts positive (negative) assortative matching along partner traits if the traits of the marriage partners are complements (substitutes) in the production of marriage output. Although marital matching among immigrants has been examined in the literature before; to the authors' knowledge this paper is the first to examine it using "household production functions" and multiple individual traits as inputs to the household production function.

Multiple individual traits namely age, education, income and hours worked, are simultaneously used to examine marital matching among immigrants. For each individual in the sample we use these four traits to construct a one-dimensional index. This index measures the individual's desirability as a mate. We then estimate household production functions for married couples using the indices as arguments. The household production functions produce parameter estimates and the signs of these estimates are used to address the issue of positive versus negative assortative matching. To judge how well the selected traits explain matching patterns in the data, the index values are used to construct a match matrix. Finally, the match matrix is used to examine whether marriages in the samples employed exhibit hypergamy (women marrying "up") or hypogamy (women marrying down).

We estimated household production functions on three samples of married couples. One sample has married couples where both spouses are immigrants. The other two samples consist of married couples where one spouse is an immigrant and the other is native born, namely native born husbands and their immigrant wives and native born wives and their immigrant husbands.

The results support positive assortative mating of spouses with respect to age and education for all samples. While this result is consistent with the existing research on marital sorting among immigrants, the result of negative assortative mating on income earned for all samples is in direct contrast with the bulk of the literature on marriage and matching. Consistent with Becker's prediction, it suggests that division of labor within the household causes 
individuals to make specific human capital investments. With respect to hours worked, while the immigrant households support Becker's theory of negative assortative mating, immigrant-native households fail to do so. They instead exhibit positive assortative mating on hours worked. Thus, our results suggest, complete specialization in immigrant households and partial specialization in immigrant-native households.

In comparing matching patterns across the three samples to isolate factors that affect marital choice, our results reveal that income earning potential of men and reproductive potential of women have the largest impact on matching behavior regardless of the sample of married couples examined. In terms of resource exchange, therefore, married couples in all our samples trade-off a man's education for a woman's age.

In terms of the degree of assortative mating or "likes marrying likes" our results reveal that while nativeborn men are more likely to marry immigrant women with similar traits, native-born women are least likely to marry immigrant men with similar traits when compared to the immigrant-immigrant matches. This is an important finding as it suggests that a larger number of native-born women are involved in marriages of convenience that provide immigrant men easy access to U.S. citizenship. Finally, the equilibrium sorting of immigrant couples provides evidence of hypergamy - females marrying up - as has been commonly assumed in discussions of marital matching. In direct contrast, in marriages between an immigrant and a native, immigrant men are more likely to marry up compared to immigrant women. Thus native-born men are found to be much more selective in choosing a partner outside socio-cultural boundaries than native-born women.

Organization of the paper is as follows. Section 2 reviews the relevant existing literature. Section 3 presents an empirical model of marital matching. Section 4 describes the data set and variables used. Section 5 presents and discusses the empirical results and Section 6 draws conclusions and suggests extensions.

\section{REVIEW OF RELEVANT LITERATURE}

Gary Becker's marriage model states that an individual decides to marry when his or her utility is greater if married than if single (Becker, 1973, 1974). Utility is a function of the marital output produced using the household production function. To maximize the production of marriage output, multiple inputs, such as individual traits, are used in the household production function. Individual traits such as age, education, income, nativity and physical appearance are considered for the production of the maximum marriage output. Becker's theory of efficient marriage markets predicts both positive and negative assortment on various individual traits. In particular, the theory predicts positive assortative matching on traits that are complements in the household production function and negative assortative matching on traits that are substitutes in the household production function. Empirical research shows that positive assortative matching occurs for traits such as education, age, and race (Jepsen and Jepsen, 2002) and negative assortative matching is likely to occur for earnings (Zhang and Liu, 2003).

Researchers have used various methodologies to empirically examine marital matching of immigrants, from simple correlations for single traits to multidimensional logmultiplicative models of association. Jasso et al. (2000) examine correlations for schooling among two types of immigrant couples using information on married couples from the Pilot for the New Immigrant Survey (NIS). They find that husband-wife schooling levels are less similar among married couples in which both spouses are immigrants than among couples involving a U.S. citizen sponsor and an immigrant spouse, except when the wife is the principal in an employment category. The authors also find that among married couples formed by U.S. citizen sponsoring the immigration of a spouse, husbands and wives have similar levels of schooling, with the U.S. citizen slightly better educated than the immigrant spouse. However, U.S. citizen husbands and their immigrant wives have substantially higher schooling than U.S. citizen wives and their immigrant husbands (on average, 2 years higher).

Focusing on a single trait, education, in a regression framework, Celikaksoy et al. (2006) finds positive assortative matching on education among first generation immigrants in Denmark. The authors investigated positive assortative matching by testing whether an individual with education above (below) a certain threshold in his or her educational distribution is more likely to marry an individual with an education above (below) the same threshold in the relevant educational distribution. Using a probit regression analysis their findings hold even when immigrants tend to import their spouses and potentially trade off education for other favorable characteristics. 
The problem with studies that analyze a single trait or characteristic is that they fail to incorporate the recognized fact that choosing a spouse is a multidimensional process. Kalmijn (1998) points out that since partners choose each other on the basis of multiple traits or characteristics, it is important to analyze more than one factor in the marriage choice. While several studies conduct multidimensional analyses of marital matching, most are limited to two dimensions. The bulk of the literature on marital matching among immigrants is focused on intermarriage. Log-linear models are commonly used to describe intermarriage when more than one dimension of the marriage choice is analyzed. For example, log-linear models were used by Pagnini and Morgan (1990) when considering education and generation and Qian, Blair and Ruf (2001) when considering education and nativity. Kalmijn (1993) considers ethnicity and education simultaneously in an analysis of spouse selection among second generation European Americans. Using the 1960 census data and applying multidimensional logmultiplicative models of association Kalmijn finds that second generation European Americans marry increasingly into the native stock. They marry increasingly out of their national origin group, and the national boundaries that separate them have become weaker over time. The author also finds that educational homogamy has increased across cohorts and concludes that changes in martial assimilation of the second generation can be characterized as a shift from national origins to education.

Unlike previous research on marital matching among immigrants, we apply a methodology never before applied to this population. We empirically examine their marriage patterns using household production functions and multiple individual traits as inputs to the household production function. In particular, we examine marital selections of immigrants on four dimensions: age, education, income and hours worked.

\section{A MODEL OF MARITAL MATCHING}

Our empirical approach follows Becker's model of marriage markets. Consider two types of agents to be matched, males $\left(M_{i}\right)$ and females $\left(F_{j}\right)$. Suppose an equal number $(N)$ of single males and single females participate in the marriage market. Individuals are heterogeneous with respect to their observed and unobserved traits $\left(X_{1}, X_{2}, X_{3}, \ldots ., X_{N}\right)$ such as education, age and health. It is assumed that the combined value of a person's traits can be used to form a one-dimensional index measuring the individual's desirability as a mate in the marriage market.

$$
\begin{aligned}
& M_{i}=g\left(X_{i}\right), i=1, \ldots ., N \\
& F_{J}=f\left(X_{j}\right), j=1, \ldots ., N
\end{aligned}
$$

These indices, then, are arguments in the household production function

$$
Z_{i j}=\gamma\left(M_{i}, F_{j}\right)=\gamma\left(g\left(X_{i}\right), f\left(X_{j}\right)\right)
$$

This approach allows individuals to perceive the overall attractiveness of a potential partner rather than base their decision on a single characteristic by making it possible for them to trade-off one characteristic for another.

The payoff matrix showing the marital output that can be produced by all possible monogamous pairings of males and females can then be written as

$$
\begin{array}{c|ccccc} 
& F_{1} & F_{2} & \cdot & \cdot & F_{N} \\
\hline M_{1} & Z_{11} & Z_{12} & \cdot & \cdot & Z_{1 N} \\
M_{2} & Z_{21} & Z_{22} & \cdot & \cdot & Z_{2 N} \\
\cdot & \cdot & \cdot & \cdot & \cdot & \cdot \\
\cdot & \cdot & \cdot & \cdot & \cdot & \cdot \\
M_{N} & Z_{N 1} & Z_{N 2} & \cdot & \cdot & Z_{N N}
\end{array}
$$


where $M_{1}, M_{2}, \ldots, M_{N}$ and $F_{1}, F_{2}, \ldots ., F_{N}$ refer to males and females of different qualities-or "type"--and $Z_{i j}$ is the marital output of a match between male $i$ and female $j$. It is assumed that a higher type $(T)$ individual of either gender is always preferred in the marriage market.

How individuals sort themselves through marriage implies ranking of individuals. Ranking males and females is a complete task, and we choose to group them in discrete categories $k$. Doing so, allows us to universally rank individuals in the marriage market such that $T_{1}<T_{2}<\ldots .<T_{k} \forall M, F$. In other words high-type males (females) occupy the higher range of $M_{i}\left(F_{j}\right)$, while the low-type males are found in the lower range of $M_{i}\left(F_{j}\right)$.

Given the rankings of males and females the optimal sorting can be derived from maximizing the aggregate output of household production, viz.:

$\operatorname{Max} Z=\sum_{i \in M} \sum_{j \in F} \alpha_{i j} Z_{i j}$

where $\alpha_{i j}$ is the permutation matrix representing the number of matches of each type. If males and females are ranked in the same order, the only optimal assignment is to associate people in a positive assortative matching along the main "core" diagonal. That is, $\alpha_{i j}$ must be a diagonal matrix

Becker (1991) shows that if an attribute of one spouse is complementary with the partner's,

$$
\frac{\partial^{2} Z_{i j}}{\partial X_{i} \partial X_{j}}>0
$$

there will be positive assortative mating with respect to that attribute. If the attributes are substitutes,

$$
\frac{\partial^{2} Z_{i j}}{\partial X_{i} \partial X_{j}}<0
$$

there will be negative assortative mating with respect to that attribute.

\section{Empirical Procedure}

To derive the optimal marriage pairings of males and females as well as the tradeoff between their individual traits, we use the method of maximum likelihood to estimate the household production function defined by equation 3. To do so, we need explicit functional forms for the individuals' index functions as well as for the production function. Any choice of functional form is necessarily arbitrary, but we are guided by several constraints. We need a functional form that allows for both increasing returns to scale - that is, individuals are better off married than single - and for individual traits to be substitutes and/or complements in production. Moreover, we need to specify a functional form for each person's index such that optimization is computationally feasible and, at the same time, allows us to recover all parameters of the production function. ${ }^{1}$ Similar to Becker (1973), we posit a CobbDouglas production function, wherein marital output is simply the product of each person's index:

$$
Z_{i j}=\gamma\left(M_{i}, F_{j}\right)=M_{i} F_{j}+\varepsilon_{i j}
$$

\footnotetext{
${ }^{1}$ These parameters are required for construction of the match matrices below.
} 
Single observed characteristics such as age, education, income etc. do not offer a perfect measure on marriageability of an individual in the marriage market. Clearly, other characteristics of marriage partners for example, beauty, personality, etc. are also important to the choice of a mate. Men and women consider potential mates on many different traits simultaneously and give varying weights to each in considering a potential spouse. However, not all the characteristics of participants in the marriage market may be observable by the researcher. We therefore, include a measurement error term $\varepsilon_{i j}$ in the measure of match quality in equation (6).

The explicit measure on match quality allows one to have a better understanding on the interaction between the two partners. We therefore assume, each person's index is to be a function of their observable characteristics

$$
\begin{aligned}
& M_{i}=e^{\alpha_{1} A^{m}+\alpha_{2} E^{m}+\alpha_{3} H^{m}+\left(1-\alpha_{1}-\alpha_{2}-\alpha_{3}\right) I^{m}} \\
& F_{j}=e^{\beta_{1} A^{f}+\beta_{2} E^{f}+\beta_{3} H^{f}+\left(1-\beta_{1}-\beta_{2}-\beta_{3}\right) I^{f}}
\end{aligned}
$$

where superscripts $m$ and $f$ refer to male and female. The four characteristics used- $A$ (age), $E$ (education), $H$ (labor market hours), and $I$ (income) - are standard characteristics studied in the literature on assortative matching (see, for example, Jepsen and Jepsen, 2002). Moreover, since they are a mix of market and non-market characteristics, they provide a good test of Becker's division of labor hypothesis - that is, negative assortative mating on labor market characteristics. The match quality can then be written as

$$
Z_{i j}=e^{\alpha_{1} A_{i}^{m}+\alpha_{2} E_{i}^{m}+\alpha_{3} H_{i}^{m}+\left(1-\alpha_{1}-\alpha_{2}-\alpha_{3}\right) I_{i}^{m}+\beta_{1} A_{j}^{f}+\beta_{2} E_{j}^{f}+\beta_{3} H_{j}^{f}+\left(1-\beta_{1}-\beta_{2}-\beta_{3}\right) I_{j}^{f}}+\varepsilon_{i j}
$$

We assume that each trait, of an individual's type, has a monotonic effect on the output of any marriage, and that higher values have the larger effect. Individuals with different attributes differ in productivity. Therefore, larger values of a given attribute are always preferred by members of the opposite gender. An obvious example of this might be education, $T$ is one dimensional, which leads on average to higher market and home productivity. Consequently, when individual traits have monotonic effects on output, the most common situation, combining the various maxima implies positive assortative mating. However, when $T$ is four-dimensional, as in our model, determination of positive (negative) assortative mating reduces to the determination of the signs of parameters $\alpha$ and $\beta$. In particular, $\alpha_{2} \beta_{2}>0$, implies that men with more schooling marry women with more schooling. That is, if potential spouses differ in their education, positive assortative mating—-likes mating likes—will characterize optimal sorting of partners if

$$
\frac{\partial^{2} Z_{i j}\left(A_{i}^{m}, E_{i}^{m}, H_{i}^{m}, I_{i}^{m}, A_{j}^{f}, E_{j}^{f}, H_{j}^{f}, I_{j}^{f}\right)}{\partial E_{i}^{m} \partial E_{j}^{f}}=\alpha_{2} \beta_{2} Z_{i j}>0
$$

That is, if $\alpha_{2} \beta_{2}>0$. Similarly, if potential spouses differ in hours worked, negative assortative mating will be optimal if

$$
\frac{\partial^{2} Z_{i j}\left(A_{i}^{m}, E_{i}^{m}, H_{i}^{m}, I_{i}^{m}, A_{j}^{f}, E_{j}^{f}, H_{j}^{f}, I_{j}^{f}\right)}{\partial H_{i}^{m} \partial H_{j}^{f}}=\alpha_{3} \beta_{3} Z_{i j}<0
$$

That is, if $\alpha_{3} \beta_{3}<0$. 
For computational ease, it is assumed that there are 5 distinct types for each sex, $M_{1}, M_{2}, \ldots ., M_{5}$ and $F_{1}, F_{2}, \ldots, F_{5}{ }^{2}$ The values for each type are determined as follows. We use arbitrary starting values for the parameters in the index functions $g\left(X_{i}\right)$ and $f\left(X_{j}\right)$ to calculate the index values for each male and female in the sample. Next the values of the $\hat{\mathrm{M}}$ 's and the $\hat{\mathrm{F}}$ 's are sorted in an ascending order and divided into 5 categories ("types"), with an equal number of men and women in each category. The number of couples in each category is used to create a $5 \times 5$ match matrix. Each person in a given category is assigned the same index value, equal to the mean value of the index for his/her type. An indicator variable is defined as $Y=1$ if the match occurs on the main diagonal, $\mathrm{Y}=0$ otherwise. Using these indicator variables the following model is estimated:

$\mathrm{Y}=1$ if $Z_{i i} \geq Z_{i j} \Rightarrow \varepsilon_{i j} \leq M_{i} F_{i}-M_{i} F_{j}=F(W)$

$\mathrm{Y}=0$ if $Z_{i i}<Z_{i j} \Rightarrow \varepsilon_{i j}>M_{i} F_{i}-M_{i} F_{j}=1-F(W)$

where $W=M_{i} F_{i}-M_{i} F_{j}$ and $\varepsilon_{i j}$ is a random error term, reflecting omitted variables, measurement error and inherent randomness in the matching process.

Assuming the error terms are i.i.d. and follow the exponential distribution, the log likelihood function is:

$\ln L=\sum_{Y=0} \ln [1-F(W)]+\sum_{Y=1} \ln [F(W)]$

Or

$\left.\ln L=\sum_{Y=0} \ln e^{-\lambda W}\right]+\sum_{Y=1} \ln \left[1-e^{-\lambda W}\right]$

where the variance of the exponential distribution, $\gamma^{2}=\frac{1}{\lambda^{2}}$, measures the dispersion in match production from the main diagonal.

As mentioned above, theory does not suggest preferred functional forms for the household production function and an individual's desirability index. Therefore, to test the robustness of our model we experimented with alternative functional forms. While these alternatives forms permit us to test for positive and negative assortative matching, they do not allow us to identify the production function parameters. Nonetheless, we find consistent results with all functional forms regarding positive and negative assortative matching on individual characteristics, suggesting our conclusions are not dependent on the choice of functional forms for the individual indices or the production function. ${ }^{3}$

\section{DATA SET}

The Integrated Public Use Microdata Series (IPUMS-USA) of the 2000 U.S. Census, a nationally representative sample of households, is our primary source of data. Although the unit of observation for the census is the household, information on all individuals residing in the household are collected. We use the 5\% sample and restrict the analyses to married heterosexual couples with at least one immigrant spouse. We exclude married couples where both individuals were born in the U.S. outlying areas or territories. After dropping observations for which information was missing on any variable a sample of 477,241 married couples remained. There are 297,962

\footnotetext{
${ }^{2}$ We experimented with the number of types of males and females in the marriage market and found that introducing this variation did not alter the results of the paper.

${ }^{3}$ Results supporting positive and negative assortative mating under the alternative specifications are available upon request from the authors.
} 
married couples where both spouses are immigrants and 179,279 married couples where one spouse is an immigrant and the other is native born.

Information about the date of the first marriage and the order of the current marriage is not available in the 2000 census. Hence, our sample of currently married couples includes couples with varying marriage durations and orders. To obtain a sample of couples who are likely to be first married and have married recently we only include married couples age 20 to 34 at the time of the census. This is the standard procedure in the literature (see for example, Qian, Blair and Ruf, 2001). With this data restriction, the sample used in our analysis consists of 97,389 married couples. There are 62,147 (63.81\%) married couples where both spouses are immigrants and 35,242 (36.19\%) married couples where one spouse is an immigrant and the other is native born. For the total sample of married immigrants the high intermarriage rate ${ }^{4}$ is a reflection of U.S. immigration policy.

The sample of married couples includes basic demographic and work variables for each individual, such as age, education, employment status, hours worked and earnings. The following are the 2000 census definitions of the demographic and work variables. Age reports the individual's age in years as of the last birthday. Education reports the individual's highest level of educational attainment. For the census samples, the reference period is the previous calendar year, thus employment status indicates whether the person had worked at all for profit, pay, or as an unpaid family worker during the previous year. Usual hours worked per week is used in the analyses and this variable reports the number of hours per week that the respondent usually worked, if the person worked during the previous year. For earnings we use wage and salary income and this variable reports each respondent's total pre-tax wage and salary income, that is, money received as an employee for the previous year. These characteristics are inputs in the empirical model of the household production function.

Summary statistics for the samples are presented in Table 1. All husbands are approximately a year older than their wives. Similar to Jasso et. al. (2000) immigrant-immigrant pairings have lower levels of schooling than the immigrant-native pairings in our samples. Irrespective of the marriage type, all husbands and all wives have similar levels of schooling. Although the native born husbands and wives have higher levels of schooling compared to their immigrant counterparts, native born husbands and their immigrant wives have higher schooling than native born wives and their husbands. In this regard our immigrant-native samples are qualitatively quite similar to Jasso et. al. (2000). However, unlike them we do not find a difference of two years in educational attainment between native husbands and immigrant wives and native wives and immigrant husbands.

Similar to Meng and Gregory (2005), we find that immigrants who marry natives earn higher incomes than immigrants who marry immigrants. The earnings premium is higher for immigrant women compared to immigrant men. In spite of this premium, however, in terms of both hours worked and the consequent income earned all husbands and wives appear to be assuming the breadwinner-caretaker traditional roles on average.

Pearson correlation coefficients are presented in Table 2. They show positive (although not perfect) assortative mating across all the traits. The individual traits of the husband have highly significant and positive association with the respective traits of the wife. For the traits that Becker characterizes as complements (age and schooling) we observe positive correlations. However, for substitute traits (earnings and hours worked) we do not observe negative correlations as predicted by Becker. Though significantly smaller in magnitude, these correlations imply that husbands and wives are positively sorted on earnings and hours worked. The correlations results, thus, provide strong support for the hypothesis that "likes" pair with "likes" with respect to individual traits. Overall, however, neither type of married couple shows a strong pattern of matching with respect to the four individual traits considered: age, schooling, hours worked and income.

\section{RESULTS}

Table 3 reports the estimates of the household production function. The estimates are qualitatively different across data sets. In particular, results using the samples on immigrant pairings suggest positive assortative mating on age and education but negative assortative mating on income and hours worked. The parameter estimates using the

\footnotetext{
${ }^{4}$ Marriage between an immigrant and a native born individual.
} 
immigrant-native samples suggest positive assortative mating on age, education and hours worked with negative assortative mating on income only. That is, the results suggest complete specialization in immigrant households but partial specialization in immigrant-native households. With respect to earnings, however, the results from all samples are completely consistent with Becker's prediction of division of labor in the household. Based on the summary statistics on hours worked and income reported in Table 1, this result is not surprising at all. Most married immigrant women in immigrant-immigrant pairings enter the US as a dependent spouse and have to go through a long waiting period before they are able to legally work. On the other hand legal working status is not an issue for an immigrant woman who marries a native born man. This is reflected in the higher working hours reported by immigrant women who are married to a native man compared to immigrant women married to an immigrant man.

Furthermore, of the four characteristics age, education, hours worked and income, while education of the husband has the largest effect on matching behavior in most samples, it is the age of the wife that affects mate selection and the organization of marriage markets for immigrants. The only exception is found in the wife nativehusband immigrant sample, where the hours worked of the husband assume more importance than education. To the extent that both education and hours worked are indicators of income earning potential the results could be considered comparable.

Since husbands and wives have traditionally had different roles and each has emphasized different qualities in a marriage partner, such tradeoffs or resource exchange between education/hours worked and age are to be expected. Marriage has often been seen as the exchange of a man's ability to make money for a woman's ability to bear children and run a household (Bergstrom and Bagnoli 1993; Weitzman 1974). While the traditional division of labor by gender has been modified by the increases in female labor force participation overtime, the socioeconomic status of the husband continues to remain more important. It follows that the outcome of the process of mate selection is almost entirely driven by the economic assets (education) of the male and the noneconomic asset (age) of the female irrespective of the demographic makeup of the samples.

Table 4 presents the estimated match matrices for all samples. As shown above, if marriage markets are efficient, matches should fall along the main diagonals of the match matrices. In each of our samples, a plurality of marriages meets this criterion. Panel A of Table 4 presents the match matrix for the marriages between two immigrants. Approximately 31.1 percent of the matches fall on the main diagonal. Assortative mating is found to be the strongest for the lowest and highest type individuals. In other words, 39 percent of $M_{1}$-type males marry $F_{1}$ type females and 40 percent of $M_{5}$-type males marry $F_{5}$-type females, whereas only 23.6 percent of $M_{3}$-type males marry $F_{3}$-type females. When there is a departure from the "core" diagonal area, the magnitudes of equilibrium sorting reveal that immigrant females are more likely to marry up than marry down. In the 68.9 percent heterogamous marriages, 35.77 percent are hypergamous (i.e., marriage between a low type female and a high type male), while 33.13 percent are hypogamous (i.e., matching of a high type female with a low type male).

Studies of mate selection provide extensive evidence supporting the generalization that hypergamy is almost universally more acceptable and more common than hypogamy (Rubin 1968; Kingsley 1941). Since the male determines social rank of his family, it is suggested that he can afford to marry down without loss of status. However, we find justification for the assumption that women "marry up" more frequently than men only for the marriages between two immigrants. In the marriages between an immigrant and a native, hypogamous marriages are more frequent than hypergamous marriages. This issue will be discussed more below.

Panels $\mathrm{B}$ and $\mathrm{C}$ of Table 3 present the match matrices for the immigrant-native born samples. While a plurality of marriages do fall on the main diagonal in each case, the marriage market for a native born husband and an immigrant wife is clearly more efficient than the marriage market for a native born wife and an immigrant husband. Compared to 34.8 percent of native husbands who married an immigrant woman like themselves, only 28.32 percent of the native wives married men with similar traits. Even more important is the comparison between the marital sorting of native born women and immigrant men with the marital sorting of two immigrants, which reveals that marriage market for the former group is significantly less efficient than the marriage market for the latter group. 
This is an important result having implications for the domestic immigration policy. One possible explanation for the least number of homogamous marriages between a native woman and an immigrant man could be that the native women are more likely to be involved in marriages of convenience which allow easy access to citizenship for immigrant men. In terms of the heterogamous marriages, panels B and C reveal that immigrant men are more likely to marry up compared to immigrant women. In other words, native born men are more selective when it comes to marrying outside socio-cultural boundaries than native born women.

\section{CONCLUSION}

This paper uses Gary Becker's theory of efficient marriage markets to examine marital matching amongst immigrants residing in the United States. In doing so, it makes four important contributions to the empirical literature on marital sorting. First, we use a significantly large (97,414 married couples) nationally representative sample of households from the Integrated Public Use Microdata Series of the 2000 U.S. Census to examine the research question. To the authors' knowledge smaller sample sizes is characteristic of the studies that have examined marital matching among immigrants previously.

Second, the bulk of existing literature uses a univariate approach - looking at simple correlations - to study marital sorting among immigrants. The marriage matching process is a function of multiple traits; such a simplification would, therefore, not be practical. We improve on the existing literature by considering the multivariate dimensions of selecting a mate. Third, we utilize the multivariate empirical methodology to assess patterns of assortative mating with respect to any particular trait, isolate factors that affect matching behaviors of immigrants and examine whether men and women trade-off one characteristic for another in the matching process. Finally, we use the estimated match matrices to determine the extent to which men and women marry "up", "down" or "equal" in the marriage markets examined.

Our results strongly support Becker's predictions of positive assortative mating with respect to age and education for all samples. The maximum likelihood estimates of our structural model also reveal negative assortative mating on a characteristic associated with labor market activity, income earned, for all samples. In this regard, our results are consistent with Becker's argument that division of labor within the household causes individuals to make specific human capital investments. With respect to hours worked, while the immigrantimmigrant households are negatively assorted on the trait, immigrant-native households exhibit positive assortative mating on hours worked. Thus, our results suggest, complete specialization in immigrant-immigrant households and partial specialization in immigrant-native households.

In comparing matching patterns across the three samples to isolate factors that affect marital choice, we find that while an indicator of income earning potential of men (education in immigrant-immigrant and husband native-wife immigrant sample; hours worked in wife native-husband immigrant sample) plays a larger role in marriage choice, it is an indicator of beauty or reproductive potential in women, age, that has the largest impact on mate selection. In terms of resource exchange, therefore, married couples in all our samples display comparable behavior; trading a man's ability to make money with a woman's ability to bear children.

Finally, the estimated match matrices reveal that the degree of assortative mating or "likes marrying likes" is highest in the husband native-wife immigrant sample and the lowest in the wife native-husband immigrant sample. This finding is worth noting. It reveals that native-born women are more likely to marry an immigrant unlike themselves in characteristics than a native-born man thereby suggesting that a larger number of native-born women are involved in marriages of convenience that provide immigrant men easy access to U.S. citizenship. Furthermore, in terms of heterogamous marriages our results suggest that while a woman "marrying up" is the most favored form of marriage amongst immigrant only families, in marriages between an immigrant and a native born immigrant men are more likely to marry up compared to immigrant women. That is, native-born men are much more selective when marrying a partner outside socio-cultural boundaries. 
Table 1: Summary Statistics: Means and Standard Deviations (in parentheses)

\begin{tabular}{|l|c|c|c|}
\hline \multicolumn{1}{|c|}{ Variable } & $\begin{array}{c}\text { Both } \\
\text { immigrants }\end{array}$ & $\begin{array}{c}\text { Wife native, husband } \\
\text { Immigrant }\end{array}$ & $\begin{array}{c}\text { Husband native, wife } \\
\text { immigrant }\end{array}$ \\
\hline Husband's age & 29.42 & 28.86 & $(3.49)$ \\
& $(3.39)$ & 27.03 \\
& 27.57 & $(3.45)$ \\
\hline Wife's age & $(3.65)$ & $13.79)$ & 27.95 \\
& $(1.24 .63)$ & 13.63 \\
\hline Husband's schooling (yrs) & $(4.45)$ & 12.49 & $(2.50)$ \\
\hline Wife's schooling (yrs) & 11.23 & $(3.39)$ & 13.46 \\
& $(4.26)$ & 13.21 & $(2.73)$ \\
\hline Husband's hours worked last week & 40.84 & $(2.55)$ & 41.89 \\
& $(15.03)$ & 41.41 & $(14.77)$ \\
\hline Wife's hours worked last week & 19.81 & $(14.88)$ & 27.52 \\
& $(20.43)$ & 29.26 & $(19.24)$ \\
\hline Husband's income (2000 dollars) & 28061.17 & $(18.31)$ & 33587.52 \\
& $(31680.31)$ & 30304.21 & $(36281.04)$ \\
\hline Wife's income (2000 dollars) & 9676.09 & $(32566.62)$ & 16456.27 \\
& $(18416.87)$ & 16381.94 & $(21221.95)$ \\
\hline N & 62147 & $(20257.52)$ & 16632 \\
\hline
\end{tabular}

Table 2: Pearson correlation coefficients

\begin{tabular}{|l|c|c|c|}
\hline \multicolumn{1}{|c|}{ Variable } & Both immigrants & $\begin{array}{c}\text { Wife native, } \\
\text { husband immigrant }\end{array}$ & $\begin{array}{c}\text { Husband native, wife } \\
\text { immigrant }\end{array}$ \\
\hline Age & 0.5765 & 0.6170 & 0.6362 \\
\hline Schooling & 0.6562 & 0.5636 & 0.5761 \\
\hline Hours Worked & 0.0175 & 0.0179 & 0.0159 \\
\hline Income & 0.0768 & 0.0681 & 0.0678 \\
\hline
\end{tabular}

Table 3: Maximum Likelihood Estimates of the Household Production Function

\begin{tabular}{|l|c|c|c|}
\hline \multicolumn{1}{|c|}{ Parameters } & Both immigrants & $\begin{array}{c}\text { Wife native, husband } \\
\text { immigrant }\end{array}$ & $\begin{array}{c}\text { Husband native, wife } \\
\text { immigrant }\end{array}$ \\
\hline Husband's age & 0.2872 & 0.2020 & 0.1861 \\
\hline Husband's schooling & 1.019 & 0.2719 & 0.5529 \\
\hline Husband's hours worked & -0.1204 & 0.4311 & 0.0714 \\
\hline Husband's income & -0.1858 & 0.0950 & 0.1895 \\
\hline Wife's age & 0.2933 & 0.3822 & 0.4199 \\
\hline Wife's schooling & 0.2739 & 0.3391 & 0.3844 \\
\hline Wife's hours worked & 0.2435 & 0.3358 & 0.3405 \\
\hline Wife's income & 0.1894 & -0.0571 & -0.1449 \\
\hline Variance & 3.6742 & 1.3362 & 1.2067 \\
\hline Log Likelihood & 71249 & 18549 & 17298 \\
\hline
\end{tabular}


Table 4: Match Matrices

\begin{tabular}{|c|c|c|c|c|c|c|}
\hline \multicolumn{2}{|c|}{ Panel A: Both Immigrants $\mathbf{3 1 . 1 0} \%$ on Diagonal; 35.77\% Hypergamy; 33.13\% Hypogamy) } \\
\hline & $F_{1}$ & $F_{2}$ & $F_{3}$ & $F_{4}$ & $F_{5}$ & Total \\
\hline$M_{1}$ & 4,876 & 2,468 & 2,153 & 1,575 & 1,357 & 12,429 \\
\hline$M_{2}$ & 3,583 & 3,318 & 2,509 & 1,917 & 1,102 & 12,429 \\
\hline$M_{3}$ & 2,014 & 2,999 & 2,941 & 2,512 & 1,963 & 12,429 \\
\hline$M_{4}$ & 1,152 & 2,316 & 2,713 & 3,216 & 3,032 & 12,429 \\
\hline$M_{5}$ & 804 & 1,328 & 2,113 & 3,209 & 4,975 & 12,429 \\
\hline Total & 12,429 & 12,429 & 12,429 & 12,429 & & 12,429 \\
\hline
\end{tabular}

Panel B: Wife Native, Husband Immigrant (28.32\% on Diagonal; 35.45\% Hypergamy; 36.23\% Hypogamy)

\begin{tabular}{|c|c|c|c|c|c|c|}
\hline & $F_{1}$ & $F_{2}$ & $F_{3}$ & $F_{4}$ & $F_{5}$ & Total \\
\hline$M_{1}$ & 1,230 & 921 & 687 & 521 & 363 & 3,722 \\
\hline$M_{2}$ & 1,014 & 915 & 870 & 564 & 359 & 3,722 \\
\hline$M_{3}$ & 691 & 749 & 813 & 840 & 629 & 3,722 \\
\hline$M_{4}$ & 472 & 630 & 701 & 930 & 989 & 3,722 \\
\hline$M_{5}$ & 315 & 507 & 651 & 867 & 1,382 & 3,722 \\
\hline Total & 3,722 & 3,722 & 3,722 & 3,722 & 3,722 & 18,610 \\
\hline
\end{tabular}

Panel C: Husband Native, Wife Immigrant (34.80\% on Diagonal; 32.12\% Hypergamy; 33.08\% Hypogamy)

\begin{tabular}{|c|c|c|c|c|c|c|}
\hline & $F_{1}$ & $F_{2}$ & $F_{3}$ & $F_{4}$ & $F_{5}$ & Total \\
\hline$M_{1}$ & 1,657 & 846 & 450 & 256 & 117 & 3,326 \\
\hline$M_{2}$ & 794 & 928 & 773 & 527 & 304 & 3,326 \\
\hline$M_{3}$ & 423 & 710 & 824 & 802 & 567 & 3,326 \\
\hline$M_{4}$ & 288 & 531 & 749 & 899 & 859 & 3,326 \\
\hline$M_{5}$ & 164 & 311 & 530 & 842 & 1,479 & 3,326 \\
\hline Total & 3,326 & 3,326 & 3,326 & 3,326 & & 3,326 \\
\hline
\end{tabular}




\section{AUTHOR INFORMATION}

Claudia Smith Kelly was born in Kingston, Jamaica. Her educational achievements include a Bachelor of Arts in Mathematics, a Masters of Science in Economics both from the University of the West Indies, Mona, Jamaica, and a Ph.D. in Economics from Syracuse University. Currently she is an Assistant Professor of Economics at Grand Valley State University in Grand Rapids, Michigan.

Sonia Dalmia earned her B.A. degree in Economics and her B.Ed. degree in Economics and Mathematics from the University of Delhi in India. She also has M.A. degrees in Economics from the Delhi School of Economics and from the University of Oklahoma. Her Ph.D. in Economics is from the University of Iowa. Currently she is an Associate Professor of Economics at Grand Valley State University in Grand Rapids, Michigan.

\section{REFERENCES}

1. Becker, G. (1973). A theory of marriage: Part I. Journal of Political Economy, 81(4), 813-846.

2. $\quad$----.-. (1974). A theory of marriage: Part II. Journal of Political Economy, 81(2), 511-526.

3. Becker, G. (1991). A Treatise on the Family, Cambridge: Harvard University Press.

4. Bergstrom, T., and Bagnoli, M. (1993). Courtship as a waiting game. Journal of Political Economy, 101, 185202.

5. Çelikaksoy, A., Nielsen, H., \& Verner, M. (2006). Marriage migration: just another case of positive assortative matching? Review of Economics of the Household, 4, 253-275.

6. Jasso, G., Massey, D. S., Rosenweig, M. R., \& Smith, J. P. (2000). Assortative mating among married new legal immigrants in the United States: Evidence from the New Immigrant Survey Pilot. International Migration Review, 34(2), 443-459.

7. Jepsen, L., \& Jepsen, C. (2002). An empirical analysis of the matching patterns of same-sex and oppositesex couples. Demography, 39(3), 435-453.

8. Kalmijn, M. (1998). Intermarriage and homogamy: Causes, patterns, trends. Annual Review of Sociology, 24, 395-421.

9. - -- Spouse selection among the children of European immigrants: A comparison of marriage cohorts in the 1960 Census. International Migration Review, 27(1), 51-78.

10. Meng, X., \& Gregory, R.G. (2005). Intermarriage and the economic assimilation of immigrants. Journal of Labor Economics, 23(1), 135-175

11. Pagnini, D., \& Morgan, S. (1990). Intermarriage and social distance among U.S. immigrants at the turn of the century. The American Journal of Sociology, 96(2), 405-432.

12. Qian, Z., Blair, S., \& Ruf, S. (2001). Asian American interracial and interethnic marriages: Differences by education and nativity. International Migration Review, 35(2), 557-586.

13. Rubin, Z. (1968). Do American Women Marry Up? American Sociological Review, 33, 750-760.

14. Ruggles, S., Sobek, M., Alexander, T., Fitch, C., Goeken, R., Kelly Hall, P., King, M., \& Ronnander, C. (2004). Integrated Public Use Microdata Series: Version 3.0 [Machine-readable database]. Minneapolis, MN: Minnesota Population Center.

15. Zhang, J., \& Liu, P. (2003). Testing Becker's prediction on assortative mating on spouses' wages. Journal of Human Resources, 38(1), 99-110.

16. Weitzman, L. J. (1974). Legal Regulation of Marriage: Tradition and Change. California Law Review, 62, 1169-1288. 